http://www.jfas.info

\title{
EFFECT OF WATER FLOWING IN CONCRETE PANEL ON THE SURFACE TEMPERATURE OF THE PANEL
}

\author{
A. Najib and M. N. Norazman* \\ Faculty of Engineering, National Defence University of Malaysia, 57000 Kuala Lumpur, \\ Malaysia
}

Published online: 10 September 2017

\begin{abstract}
This research is done to study the effect of water flowing inside a concrete panel to the temperature on the surface of the panel as a way to decrease or increase the temperature in a building. This is part of the effort addressing green building system. The objectives of this research are to discover the potential for green building material or technique in order to reduce energy in building. By using specified size slab of $1500 \mathrm{~mm} \times 500 \mathrm{~mm}$ with thickness of $125 \mathrm{~mm}$, and using concrete grade M30 with embedded PVC pipes in the slab with inlet and outlet for flowing water. The result show that using tap water, in 50 minutes, the slab temperature reduced by $10 \%$ from $30^{\circ} \mathrm{C}$ to $27^{\circ} \mathrm{C}$. Using cold water of less than $10^{\circ} \mathrm{C}$, the temperature of the slab is decrease $19 \%$ with lowest temperature recorded is $22^{\circ} \mathrm{C}$. While, by using hot water, the temperature of the slab surface increased by $13 \%$ to $34^{\circ} \mathrm{C}$.
\end{abstract}

Keywords: slab cooling; slab heating; green building; water in slab; energy management.

Author Correspondence, email: azman@upnm.edu.my

doi: http://dx.doi.org/10.4314/jfas.v9i3s.14 


\section{INTRODUCTION}

\subsection{Green Building Materials and Technology}

Buildings are one of sources that consume greatest energy. In order to reduce energy in building, energy management must be careful plan to capture the most energy savings potential. There are a few factors that influence low energy concept such as design concept, building material used and construction technology. Furthermore, this initiative can also achieve cleaner environments, decreased in fuel bills, and lower carbon released [1-6].

The Malaysia Energy Commission Diamond Building is the latest and most advanced example of a government building in Malaysia, which integrates a comprehensive list of energy efficient features. It is located at Precinct 2, Putrajaya adjacent to a landscaped garden. This building was conceived as a showcase building, which has adopted both passive and active design features in the best way and utilizes the latest technology available in the country as it is a showcase sustainable building [7].

The Diamond Building uses roof and floor slab cooling. Flexible $22 \mathrm{~mm}$ Polyethylene of Raised Temperature resistance (PERT) chilled water pipes are embedded in the RC floor slabs during construction to function as a thermal storage system in the building. At night, cold water will run through the pipes Thus, the temperature of the floor slabs will decrease to $20^{\circ} \mathrm{C}$. These will then absorb the heat gain from people, computers, solar gain etc. and radiate cooling to the occupants during daytime. This kind of floor slab cooling not only lowers energy consumption, but it also can reduce the size of AHU (Air-handling Unit) room by about $30 \%$ since the cooling task have shifted partially to the slabs.

It contributes to energy savings because it reduces the reliance on conventional air-conditioning systems and by reducing the size of the AHU room, less power is needed for air-conditioning. Concrete slabs are charged at night with chilled water $18{ }^{\circ} \mathrm{C}$ to $20^{\circ} \mathrm{C}$. The temperature of the surface slab is at $20-23{ }^{\circ} \mathrm{C}$.

A 71.4 kilowatts peak $(\mathrm{kWp})$ photovoltaic $(\mathrm{PV})$ rooftop system has been installed on the Diamond Building, this is a typical example of aesthetic integration of mass-produced PV modules into a rooftop. The shape of the building allows for a bigger area on the ground for greenery, while the larger roof area provides space for solar panels. Solar power supplies 
about $10 \%$ of the energy used in the building. Second generation thin film Photovoltaic (PV) panels are used. The thin film solar panels are cheaper compared to the first generation silicon solar panel although the energy efficiency is lower. Copper Indium Gallium Selenium (CIGS) is applied to a substance such as foil or glass. CIGS is more stable compared to other forms of thin film materials. Another advantage of thin film solar panels is they are 100 times thinner than the silicon based solar panels. That translates into lightweight, portable and compact architecture design. The Diamond Building BIPV system is equipped with sensors to measure ambient and module temperature, solar irradiance and wind speed. Data loggers are used to collect performance data to evaluate the effectiveness of the BIPV system installed.

The unique design of the Diamond Building also means that modules were placed on all 4 sides, facing North, South, East and West, so that it can be used to gather performance data from all sides of the building. The use of building-integrated photovoltaic (BIPV) does not contribute to energy savings in the building. Instead, it is a means of generating more energy for the consumption of the building resulting in a lower Building Energy Index (BEI).

The daylight design of the atrium consists of three key design elements which are an automated blind that regulates light penetration into the atrium, different window sizes for each floor and reflective aluminium panels. The automated atrium glazing roller blind consists of 24 individual blinds that can form six configurations depending on the outdoor light levels. The blinds allow $30 \%$ of the light through to ensure daylighting for the offices facing the atrium even when the atrium blinds are fully engaged. Two light sensors on the atrium glazing control the blind operation. The principal control strategy aims to block direct sunlight penetration into the offices and to moderate the light level in the atrium. Daylight availability decreases deeper into the atrium. For the upper floors, windows are replaced with white walls to reflect light deeper down the atrium while floor-to-ceiling windows are used for the lower floors. Aluminium panels mounted on the fourth and fifth floor of the atrium walls reflect light to the first and second floors [8].

\subsection{Radiant Surface}

Some types of concrete slabs may be more suitable to a particular site and climate zone than others. Firstly, slab on the ground is the most common and has two variants which are 
conventional slabs with deep excavated beams and waffle pod slabs. They sit near ground level and have a grid of expanded polystyrene foam pods as void formers creating a maze of beams in between. The conventional slabs can be insulated beneath the broad floor panels that waffle pods are by definition insulated beneath. Both may benefit from slab edge insulation. Secondly, suspended slab are formed and poured in situ with either removable or non-load bearing formwork, or permanent formwork which forms part of the reinforcement. Then, precast slab is manufactured off site and craned into place, either in finishes form or with an additional thin pour of concrete over the top. They can be made from conventional or post-tensioned reinforced concrete, from autoclaved aerated concrete (AAC) [9].

Slab cooling is one of the methods to decrease the temperature of the slab surfaces. Radiant surface is an exposed building surface with tubes or piping configuration installed within for heating in a conditioned space. The radiant surfaces may be for heating or cooling. The network of radiant surface pipes can turn the radiant surface such as floors, walls and ceiling of a conditioned space into cooled surfaces that evenly absorb sensible heat energy such as radiant energy from solar gain, people, lights and computers, in addition to convective heat transfer from the air. Besides, the radiant cooling system is typically designed in conjunction with radiant heating, radiant cooling systems circulate chilled fluid through the same network of pipes where warm fluid circulates during the heating season [10].

This network of pipes can turn the floors, walls and ceiling of conditioned space into cooled surfaces that evenly absorb heat energy. Radiant cooling works best in tightly sealed building that integrates radiant with a downsized forced-air system to meet the building's fresh air requirement [11].

\section{METHODOLOGY}

This section describes the ways sample are prepared and data are obtained and ensure analysis of the study proceed smoothly and effectively to achieve the objectives, the importance of this study is to assess the benefits to be used as a reference to enhance green building.

Concrete slab come in many forms and can be used to provide great thermal comfort. Slabs can be on the ground, suspended, or mix both. They can be insulated, both underneath and on 
the edges. Conventional concrete has high embodied energy. It has been the most common material used in slabs.

The sample use is a slab with the size of $1500 \mathrm{~mm} \times 500 \mathrm{~mm}$ with $125 \mathrm{~mm}$ thickness. The piping with inlet and outlet was installed in the slab formwork using $50 \mathrm{~mm}$ PVC type prior to concreting work. Wire mesh and reinforcement bar can be used to strengthen the concrete to the desired strength. Concrete grade M30 is used in this experiment as shown on Fig. 1.

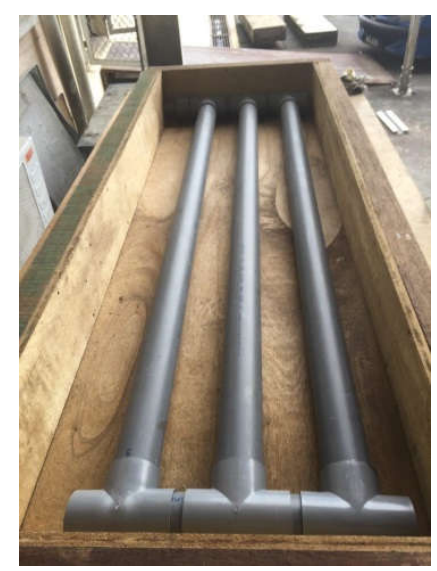

a) PVC pipes inside the panel

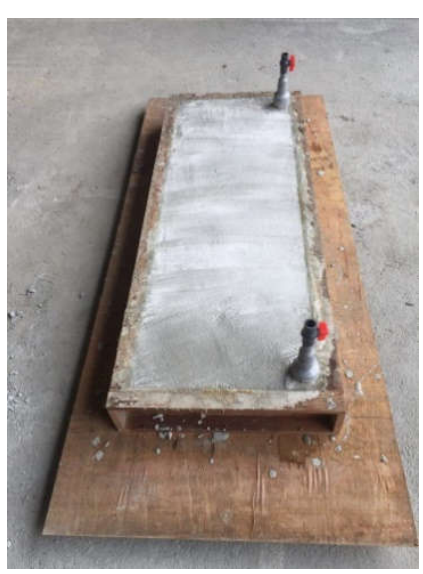

b) Casted slab panel

Fig.1. Panel preparation and testing

Data obtained from experimental work are the temperature of the slab relative to the temperature of liquid used. The temperature of the surfaces of the slab is different according to time. The liquid use is tap water, cold water and hot water. Among the data captured in this study are the changes of temperature and humidity of air surrounding the concrete slab.

Many variations of cooling system in the building can increase the energy usage in the building. So, by utilizing the slab cooling effect after cold water running into the slab, we can reduce the temperature inside the building much more. It will enhance the energy saving use for Air Handling Unit (AHU) in building.

\section{RESULTS AND DISCUSSION}

The first three experiments conducted is by running water inside the slab for 50 minutes. The water use is tap water at $24^{\circ} \mathrm{C}$, cold water at $6^{\circ} \mathrm{C}$ and hot water at $55^{\circ} \mathrm{C}$. Result obtained are as shown on Fig. 2. The top-most line indicated effect from hot water running in the PVC pipes 
inside the slab makes temperature increases with time. The highest temperature of the slab surface is $34^{\circ} \mathrm{C}$. Next, the tap water use and the temperature goes down from $30^{\circ} \mathrm{C}$ to $27^{\circ} \mathrm{C}$. Lastly, using running cold water and the lowest temperature recorded is $22^{\circ} \mathrm{C}$. The hot water can increase the surfaces temperature by $13 \%$ in 50 minutes, while the cold water can reduce surface temperature by $19 \%$ in 50 minutes.

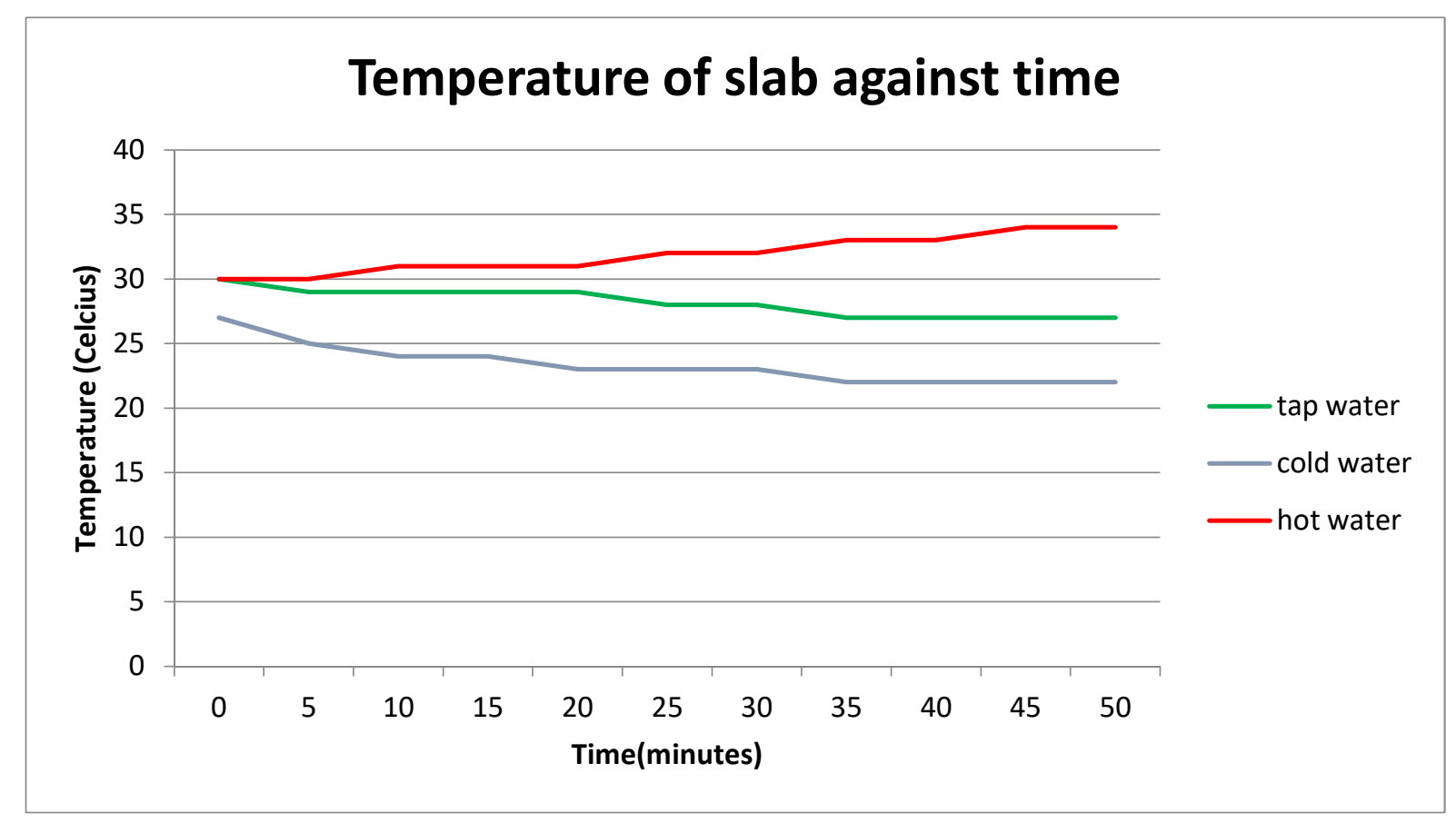

Fig.2. Effect of 50 minutes running water in slab to slab surface temperature

Fig. 3 shows result of another experiment. The first 40 minute is the water running through the pipe inside the slab cooling. Then, from minute 41 to 80 , water is stagnant inside the panel. From the graph above, the top-most line indicated the temperature of hot water is steadily increased until 40th minute under running hot water and then slowly fell until 80th minute when the water stops running. Secondly, the middle line indicated the tap water that only gently drop the temperature from $30^{\circ} \mathrm{C}$ until $27^{\circ} \mathrm{C}$ even when the water stops in the last 40 minute. After that, the bottom-most line indicates a cold water that show the temperature decrease until $22^{\circ} \mathrm{C}$ under running cold water and increase back to $24^{\circ} \mathrm{C}$ when the water stops running. 


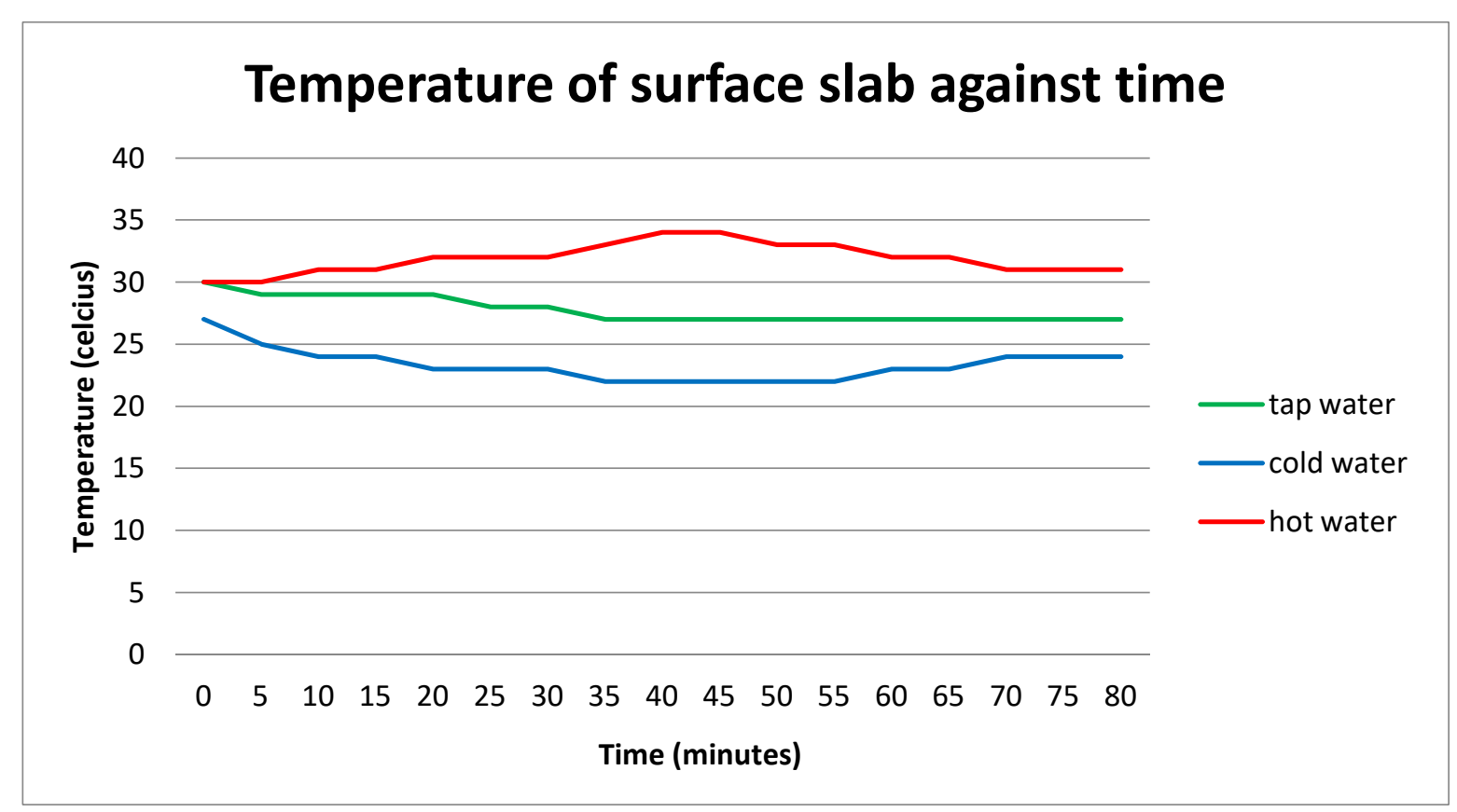

Fig.3. Effect of 40 minutes running water followed by 40 minute still water in slab to slab surface temperature

\section{CONCLUSION}

The objectives of the study are to identify best design concept to reduce energy requirement, to discover the green building material used to reduce energy in building and to study the effects of hot and cold water in the slab cooling [12-14]. The temperature performance of concrete slab with water running in PVC pipe in the slab can be explained by the data obtained above. We discover that using tap water the temperature reduced up to $3^{\circ}$ from the initial temperature of $30^{\circ} \mathrm{C}$. Next, on the effect of using cold water we find that the temperature of the slab is decrease for $5^{\circ}$ and lowest temperature recorded is $22^{\circ} \mathrm{C}$. By using hot water, the temperature of the slab surface increased by $4^{\circ}$ form $30^{\circ} \mathrm{C}$ to $34^{\circ} \mathrm{C}$. Keeping the water stagnant for 40 minute, the hot water panel temperature drops back to $31^{\circ} \mathrm{C}$ just $1{ }^{\circ} \mathrm{C}$ above initial value while for cold water the temperature settles halfway at $24^{\circ} \mathrm{C}$. While, for tap water the temperature maintain at $27^{\circ} \mathrm{C}$ even after 40 minutes. This information is useful if we intend to stop the water flowing intermittently in order to save energy. For future research, we can try metal pipe, where metal is a better conductor than PVC. However, metal pipe will cost more and might require skill plumber. The slab cooling could have achieved lower temperature if using metal pipes. 


\section{ACKNOWLEDGEMENTS}

The author extends his utmost gratitude to the Ministry of Higher Education Malaysia, and the National Defence University of Malaysia for funding this research.

\section{REFERENCES}

[1] Burnett J. City buildings-Eco labels and shades of green! Landscape and Urban Planning, 2007, 83(1):29-38

[2] Paul W L, Taylor P A. A comparison of occupant comports and satisfaction between a green building and a conventional building. Building and Environment, 2008, 43(11):1858-1870

[3] Cole R J. Transition from green to regenerative design. Building Research and Information, 2012, 40(1):39-53

[4] US Environmental Protection Agency (EPA). Green building. Washington DC: EPA, 2016

[5] Saunier R. E., Meganck R. A. Dictionary and introduction to global environmental governance. London: Earthscan, 2012

[6] Griffith T. Jacobs Institute for Design Innovation: Project overview design and innovation. California: Forell/Elsesser Engineers Inc. 2016

[7] Othman D S R. Sustainable development initiatives in Malaysia II: An insight on energy commission and green buildings. Selangor: Malaysia Productivity Corporation, 2014

[8] Xin H Z, Rao S P. Active energy conserving strategies of the Malaysia energy commission diamond building. Industrial Management and Data System, 2012, 106(8):1112-1132

[9] Dick C. Concrete slab floors. Australia: Your Home, 2013, pp. 254-260

[10] Bhanware P. Radiant cooling system classification and basics of slab cooling. Building Energy Efficiency Project (BEEP). Energy, 2016, 22:661-667

[11] Mills C A. Radiant cooling systems. US patent 3,001,382, 2,966,780 and 2,971,350. 1961

[12] Mazlan M, Mohd H M A, Muhammad A S, Mohamad B A B, Mohamad N M, 
Muhammad I A, Nik A A N Y, Mohammad K A A R, Zairi I R, CFD simulation using wood (cengal and meranti) to improve cooling effect for Malaysia green building. ARPN Journal of Engineering and Applied Sciences, 2015, 10(20):9462-9467

[13] Siti A I, Mazlan M, Sitti F M R, Mohd H M A, Abdul A M S, Zairi I R. Biocomposite material to enhance heat transfer of wood (shorea faguetiana and palaquim $\mathrm{sp}$ ) for green building in Malaysia. ARPN Journal of Engineering and Applied Sciences, 2015, 10(1):301-312

[14] Amalina A, Mazlan M, Hamid Y, Mohd H M A, Abdul A M S, Zairi I R. The enhancement of heat transfer of wood (neobalanocarpus heimii, shorea sp, instia palembanica miq) of bio-composite materials for green building in Malaysia. ARPN Journal of Engineering and Applied Sciences, 2015, 10(1):357-369

\section{How to cite this article:}

Najib A, Norazman MN. Effect of water flowing in concrete panel on the surface temperature of the panel. J. Fundam. Appl. Sci., 2017, 9(3S), 167-175. 